Revista de Estudios Histórico-Jurídicos

[Sección materiales]

XLII (Valparaíso, Chile, 2020)

[pp. 835-855]

\title{
ANDRÉs BELlo EDITOR DE DERECHO MINERO FRANCÉS. REEDICIÓN DE UNA TRADUCCIÓN Y DE SU MANUSCRITO SUPUESTAMENTE INÉDITO
}

[Andrés Bello editor of French Mining Law. Re-edition of a Translation and its supposedly unpublished Manuscript]

\author{
Alejandro Vergara Blanco* \\ Pontificia Universidad Católica de Chile
}

\begin{abstract}
Resumen
Se reproduce, con agregados y algún aparato crítico, un texto sobre derecho minero francés publicado en dos partes por Andrés Bello en El Araucano en el año 1842, con el título de "Curso de Derecho Administrativo por $M$. Cotelle: 3 tomos $8 .^{\circ}$ Paris". Este texto venía siendo atribuido a Bello como autor, a pesar de que es su traductor. Se muestra, además, la conexión de este texto con un manuscrito de Bello, que resulta ser el borrador de esa traducción, del que se conserva únicamente la última hoja. Las breves anotaciones iniciales se refieren al contenido y relevancia de ese texto para el estudio de las fuentes del derecho minero chileno y a las posibles motivaciones de Bello para publicarlo, dada la época en que se realizó.
\end{abstract}

\section{Palabras Clave}

Andrés Bello (manuscrito) - derecho de minería (historia del) - derecho administrativo (francés) - historia del derecho del siglo XIX - El Araucano.

\section{AbSTRACT}

A text on French mining law published in two parts by Andrés Bello in $E l$ Araucano in 1842, with the title of "Administrative Law Course by M. Cotelle: 3 volumes 8, Paris", is reproduced with aggregates and some critical apparatus. This text was being attributed to Bello as an author, although he is its translator. It also shows the connection of this text with a manuscript of Bello, which turns out to be the draft of that translation, of which only the last sheet is preserved. The brief initial notes refer to the content and relevance of this text for the study of the sources of Chilean mining law and the possible motivations of Bello to publish it, given the time it was made.

\section{KEY WORDS}

Andrés Bello (manuscript) - Mining Law (history of) - Administrative Law (French) - History of 19th century law - El Araucano.

RECIBIDO el 19 de agosto de 2019 y ACEPTADO el 24 de enero de 2020

* Profesor titular de Derecho Administrativo, Facultad de Derecho, Pontificia Universidad Católica de Chile. Av. Libertador Bernardo O’Higgins 340, 4o piso. Dirección electrónica: alvergar@uc.cl 


\section{ANOTACIONES INTRODUCTORIAS}

En estas breves notas iniciales me refiero a tres aspectos relacionados con los textos que reedito (la traducción y el manuscrito). Primero, describo y sitúo el origen del texto traducido y del manuscrito relacionado; luego, puedo conectar su publicación con la posición de Bello como redactor de El Araucano; y, en fin, con la época en que fue publicado, la que coincide con conocidas preocupaciones y encargos de Bello. Acaso esto puede servir de contexto para una lectura actual de ese texto sobre derecho minero francés y su conexión con la historia del derecho minero chileno, en especial aquella historia posterior a 1842 , fecha de su publicación.

\section{Una hoja manuscrita de Bello supuestamente inédita}

En mayo de 1842 Andrés Bello publicó en la sección variedades de El Araucano la traducción de una reseña bibliográfica relativa al derecho minero francés, texto que previamente habíase publicado en Le Moniteur Universel, periódico francés de una línea editorial muy similar a El Araucano, en su ejemplar de 19 de noviembre de 1841. Esta publicación, como muestro más adelante, venía siendo atribuida a Bello como autor y no como su traductor, que es lo real.

Además, cabe consignar que el papel manuscrito en que Bello realizó la traducción (que es el borrador que seguramente entregó en la imprenta) pudo haber seguido el destino usual de los papeles que ya cumplen su función y son, desde el punto de vista editorial, superados por el texto impreso posterior: el cesto de la basura. No obstante, solo la última hoja de ese manuscrito sobrevivió, la cual quedó entre los papeles que Bello dejó al morir. Esa hoja suelta, que reproduzco al final en Anexo, se conserva en la Colección de manuscritos de Bello.

Hasta ahora, no se había conectado este manuscrito (que aún se puede consultar en su estado original) con la publicación de 1842 que señalo antes, pero resulta que corresponde a las últimas líneas de esa publicación. Parecía que existían dos escritos distintos de Bello sobre la materia minera, pero en realidad ambos son parte de la misma publicación, sólo que uno es el texto editado y el otro es parte de su manuscrito borrador.

Hemos reconstruido la historia completa de este papel considerado hasta ahora uno de los inéditos de Bello. Para mayor claridad relato la génesis del texto en orden cronológico, junto a otros antecedentes del caso. No obstante que, como es usual, la historia de la investigación que dio lugar a esta reedición de los textos de Bello, se realizó inversamente, desde el presente hacia el pasado, hasta dar con sus orígenes editoriales.

En Anexo realizo la transcripción de la traducción publicada por Bello; además, ofrezco una comparación con el original publicado en francés, en especial por el hecho de que Bello prescindió de algunos párrafos y notas de ese original, seguramente por una cuestión de espacio; textos estos que ofrezco también, traducidos, en el lugar que corresponde según su original. 


\section{Decurso editorial de la traducción de Bello}

Muestro los tres momentos relevantes de esta traducción: la edición en Francia del texto original traducido; la edición de su traducción en Chile, y luego el curso editorial y referencias de la misma.

\section{a) texto original publicado en Le Moniteur Universel en 1841}

En el N 323 de Le Moniteur Universel, del viernes 19 de noviembre de 1841, de cuatro páginas, en las dos finales (pp. 2.353 y 2.354), sección "Jurisprudence", se publicó una recensión escrita por De Cheppe ["maître des requétes, chef de la division des mines au ministère des travaux publics"] sobre un manual de derecho administrativo, el Cours de droit administratif de M. Cotelle; reseña que fijaba su atención en especial (casi únicamente) sobre una parte de esa obra: la relativa a las minas ${ }^{1}$. Esa recensión llama la atención de Bello, y como veremos, la traducirá y publicará muy pronto, en mayo del año siguiente. El ejemplar físico del Moniteur Universel que estuvo en las manos de Andrés Bello se encuentra actualmente perdido, ya que no existen rastros de él ni en la Biblioteca Nacional ni en el Archivo Central Andrés Bello.

El periódico francés Le Moniteur Universel data del año 1789 y se editó hasta 1868. Su difusión se extendió por Europa y Estados Unidos. Tuvo un rol importantísimo durante la revolución francesa, pasando luego a tener el carácter de diario oficial del gobierno francés por un tiempo bastante prolongado. Seguramente el gobierno chileno de la época, a instancias de Bello, había realizado una suerte de suscripción de ese semanario.

\section{b) traducción de Bello publicada en El Araucano en 1842}

Solo seis meses después Andrés Bello ya había traducido ese texto, en su mayor parte, y lo publicó en la sección Variedades de El Araucano, en mayo de 1842. La publicación en El Araucano se realizó en dos partes, la primera el 13 de mayo

\footnotetext{
${ }^{1}$ Es usual en la literatura francesa, citar esa recensión de De Cheppe, así: $M$. de Cheppe, Cours de droit administratif de $M$. Cotelle et plus spécialement sur la partie relative aux mines, en: Moniteur universel, 19 novembre 1841, France. Dejando así claro que esa recensión aborda especialmente el tema del derecho minero y no los aspectos de derecho administrativo de esa obra. El autor del libro reseñado es el jurista francés Toussaint-Ange Cotelle (1795-1879) y su Cours de droit administratif applique aux travaux publics, Paris, 1839, 2 volúmenes, reseñado por De Cheppe, actualmente puede ser consultado en la Biblioteca Nacional de Chile, Sección Fondo General. Se trata de un libro especializado, aplicado a las obras públicas y minería, para ser utilizado por los alumnos de la Escuela de Puentes y Caminos, y no de un curso de derecho administrativo general para alumnos de derecho. De ahí la desconexión de este libro de Cotelle con la manualística clásica de derecho administrativo francés; en efecto, con posterioridad casi no es citado ni considerado por los autores de derecho francés del siglo XIX o comienzos del siglo XX, como es el caso de los dos autores más relevantes de la época: Henry Berthélemy (1857-1943), autor de un Traité élémentaire de droit administratif, de 1913; o de Maurice Hauriou (1856-1929), autor de un Précis de droit administratif: contenant le droit public et le droit administratif, de 1893. En Chile, tampoco lo citará Luis Claro Solar, en su Curso de derecho civil chileno y comparado, a pesar de haber tenido a la vista, como se sabe, un amplio caudal de textos franceses de derecho administrativo.
} 
de 1842 y, la segunda, el 20 de mayo del mismo año; la primera ocupa las dos primeras páginas del periódico, mientras que la segunda, ocupa solo la primera² ${ }^{2}$.

En la primera nota que acompañaba a esa publicación, escrita por Bello, se justifica la publicación de este texto así: "Este artículo tiene tantas aplicaciones a nuestro régimen administrativo, que nos ha parecido digno de una lectura atenta".

Pero, el texto si bien hace una referencia al derecho administrativo en su título, su contenido real está referido en su mayor parte a la legislación de minas francesa y a algunas discusiones desarrolladas sobre el tema en ese país. Agrega además Bello en esa nota, que: "Lo hemos traducido del Monitor Universal', dejando así en claro que no es de su autoría. Al final de la segunda parte del mismo, no olvidó Bello de poner el nombre de su autor: "De Cheppe".

\section{c) referencias posteriores a la traducción y su atribución a Bello}

No obstante el cuidado de Bello en esa primera nota, ya veremos que, en la historia editorial que sigue, este texto pareciera que ha quedado oculto a la atención de los especialistas de derecho minero (seguramente a raíz del título equívoco del mismo) y ha sido atribuido erróneamente a Bello o, al menos, se ha editado de un modo que ha dejado dudas al respecto. Lo podemos comprobar en las únicas referencias relevantes que conocemos sobre este texto:

i) el escrito fue recogido en las Obras completas de don Andrés Bello, de $1893^{3}$, lo cual ya es extraño por no ser de su autoría; pero podría haber sido adecuado en la medida que se aclarase el punto; lo que no sucedió. En efecto, fue editado bajo el título: "Curso de derecho administrativo por M. Cotelle, 3 tomos $8^{\circ}$ Paris", retomando el título que anota Bello en la primera parte de la edición de 1842 en El Araucano. No obstante que en nota al pie se copia la advertencia de la primera nota de Bello, al igual que en la publicación de El Araucano en 1842 ("Lo hemos traducido del Monitor Universal"), al final del mismo se omite incluir la referencia al autor francés y desaparece la firma "De Cheppe", que aparecía en la edición original realizada por Bello. Esto pudo originar en los lectores, es evidente, la impresión equivocada de que se trataría de un escrito de Bello. Esa impresión surge, a pesar de la inclusión de la nota inicial, por el solo hecho de haberse incluido en las obras completas de Bello sin advertir el editor, de un modo más claro que, en realidad, se trata de un texto escrito por otro autor, únicamente traducido por Bello.

ii) otra referencia que encontramos sobre esta traducción corresponde a

${ }^{2}$ Las dos partes tienen la siguiente descripción editorial: i) la primera, en El Araucano $\mathrm{N}^{\circ}$ 612, de 13 de mayo de 1842, p. 1 (columnas 1,2 y 3) y p. 2 (col. 1), bajo el título: "Curso de derecho administrativo por M. Cotelle: 3 Tomos $8^{\circ}$, París". Al inicio de este primer texto se incluye una nota sobre el interés del tema (nota que es seguro que es de Bello). ii) la segunda, en El Araucano N ${ }^{\circ}$ 613, de 20 de mayo de 1842, p. 1 (columnas 1, 2 y 3), bajo el título: Curso de derecho administrativo aplicado a las obras públicas: por M. Cotelle (Conclusión)". Al final de este segundo texto aparece firmado por: "(De Cheppe)", en que Bello, como redactor, dejaba huella del autor del texto original.

${ }^{3}$ Véase: Obras completas de don Andrés Bello ([edición hecha bajo la dirección del Consejo de Instrucción Pública] Santiago, Imprenta Cervantes, 1893), XV, pp. 259-270 [sección Miscelánea]. 
Amunátegui, quien, sin mayor precisión, refiriéndose a la actividad editorial de Bello en El Araucano, señala que "el Curso de derecho administrativo por Mr. Cotelle, fué también acojido con aplausos por El Araucano". ${ }^{4}$ Pero no profundiza más en el tema.

iii) una referencia que cabe agregar (y que es de una omisión): este texto no fue incorporado en las obras completas posteriores de Andrés Bello, del siglo XX 5 . Esta omisión, seguramente, es indicativa de una revisión más acuciosa de sus editores.

No he encontrado otra referencia específica a esta traducción de Bello en la literatura posterior a su edición ni en la más actual. Pareciera que no ha despertado interés en los especialistas de derecho minero, quizás por el modo ambiguo en que ha sido editado y reeditado, sobre todo por no hacer referencia directa en su título a la disciplina del derecho minero, sino al derecho administrativo. Ello, sin perjuicio del posible interés que tiene para la discusión de la naturaleza jurídica del dominio de los minerales que, como señalo al final de estas anotaciones, tuvo por base legal relevante lo consignado por Bello en el art. 591 del Código Civil de 1857.

\section{Historia archivistica paralela de la hoja suelta de Bello supuestamente inédita}

Pero antes cabe referirse a un antecedente archivístico que hasta ahora no había sido vinculado con la traducción de 1842, pues resulta que esa traducción está conectada genéticamente con una hoja suelta de Bello, constituyendo esta la última página del manuscrito en que Bello realizó la traducción; habiéndose perdido, hasta ahora, el resto de las hojas.

En el Catálogo de manuscritos de Andrés Bello, de $1965^{6}$, que se encontraban a la fecha en la Biblioteca de la Universidad de Chile (del que da noticia Alejandro Guzmán Brito en 1982) ${ }^{7}$, aparece la siguiente referencia a un papel deteriorado: “77) Derecho de Minería. Apuntes para un comentario sobre un libro de M. Cotelle acerca del derecho de minas. Incompleto. 1 hoja de $330 \times 215 \mathrm{~mm}$, escrita por Bello (deteriorada)".

Como se lee, la descripción que se hace del texto da la impresión de tratarse

${ }^{4}$ AmunÁtegui Reyes, Miguel Luis, Nuevos estudios sobre don Andrés Bello (Santiago, Imprenta, litografía y encuadernación Barcelona, 1902), p. 120.

${ }^{5}$ Las obras completas editadas en Caracas, en especial su tomo XVIII, relativo a la materia jurídica, no lo contiene. Véase: Obras completas de Andrés Bello (Caracas, Fundación La Casa de Bello, 1982), XVIII.

${ }^{6}$ Véase: Catálogos de la Biblioteca Central de la Universidad de Chile, $\mathrm{N}^{\circ} 1$, Colección de manuscritos, I: Papeles de don Andrés Bello. Prólogo por Alamiro de Ávila Martel (Santiago de Chile, 1965).

${ }^{7}$ GuZMÁn BRITO, Alejandro, Andrés Bello codificador: historia de la fijación y codificación del derecho civil en Chile (Santiago, Ediciones de la Universidad de Chile, 1982), II, p. 409, el que, además, publica parcialmente dicho catálogo en que aparece, entre otras referencias, en p. 419, la que copio más adelante en el cuerpo. Fue en verdad esta referencia la que primero me llamó la atención al leer el libro de Guzmán, y el resultado es que al ir en su búsqueda, después de varios derroteros, me he encontrado con el resto de las piezas a que aquí hago referencia de un modo cronológico. 
de un papel inédito ${ }^{8}$, el cual se dice, se encuentra incompleto y deteriorado, y se trata sólo de una hoja cuyo estado no es óptimo.

La referida hoja puede ser actualmente consultada como manuscrito en el Archivo Central Andrés Bello, de la referida Universidad, o por vía electrónica?, con la siguiente indicación (proveniente de la descripción de ese catálogo de 1965): "Derecho de minería: apuntes para un comentario sobre un libro de M. Cotelle acerca del derecho de minas".

La trascrita descripción de dicho papel parece atribuirlo a Bello como autor (“apuntes para un comentario sobre un libro"). Pero, de la trascripción y comparación que hacemos en el anexo, al final, podemos apreciar que este manuscrito de Bello se corresponde exactamente con los últimos párrafos de la traducción publicada en 1842. De lo que resulta que ese papel suelto viene a ser la última hoja del que fue el borrador manuscrito de Bello de esa traducción luego publicada en El Araucano.

De ahí que, eventualmente, el Archivo Central debiese realizar alguna referencia adicional al hecho de tratarse de una hoja suelta de una traducción.

\section{La posición de Bello en El Araucano}

Una vez dilucidado el origen y la conexión de la traducción publicada en 1842 con la hoja manuscrita que se resguarda en el archivo de Bello, cabe observar el contexto histórico de su publicación, y así comprender la motivación que Bello tuvo a la vista para hacerla.

El texto fue publicado por Bello como redactor de El Araucano, posición que desempeñaba desde 1830 en conjunto con Manuel Gandarillas, y luego en solitario desde 1835 hasta $1853^{10}$. El progreso del periódico estuvo fuertemente ligado a la labor intelectual y periodística de Bello, quien fue determinante en el desarrollo del perfil del medio ${ }^{11}$. De hecho, este periódico se ubicaba en un nivel distinto y superior a la lucha política entre grupos y personalidades; fue portavoz, no solo del

${ }^{8}$ La descripción que da GuZMán Brito, Alejandro, cit. (n. 7), II, p. 409 de los papeles contenidos en ese catálogo es la siguiente: "En la Sala Domingo Edwards Matte de la Biblioteca Central de la Universidad de Chile (Santiago) se encuentra depositado un riquísimo fondo de papeles que en su día pertenecieron a Bello, entre los cuales existen muchos de carácter jurídico. Salvo algunas excepciones, ellos no han sido editados. [...] En los casos de piezas editadas, ello se indica”. Cabe agregar que respecto de este papel nada se indica, lo que aumenta la sensación de papel inédito.

9 Visible en: https://uchile.alma.exlibrisgroup.com/view/delivery/56UDC_ INST/12171956630003936, [última visita: 28 de julio de 2019]. En ese sitio se ofrece la siguiente información, que no resulta ser efectiva: "Date: [entre 1845 y 1865]", pues es evidente que fue escrito, con toda probabilidad, a inicios de 1842; por la segura demora en llegar a Chile (vía marítima) un periódico aparecido en Francia el 19 de noviembre de 1841. Cabe señalar, además, que el manuscrito que aquí analizo es el contenido en el anverso de ese papel, pues el reverso contiene un manuscrito de Bello de otra materia.

${ }^{10}$ GuZmán Brito, Alejandro, Vida y obra de Andrés Bello (Santiago, Editorial Globo, 2009), p. 40.

${ }^{11}$ Santa CruZ, Eduardo, La prensa chilena en el siglo XIX. Patricios, letrados, burgueses y plebeyos (Santiago, Editorial Universitaria, 2010), p. 22. 
gobierno, sino que también de la política gubernamental ${ }^{12}$. En particular, Bello se desempeñaba en las secciones Exterior y Variedades, editorializando con cierta frecuencia temas de política internacional, administración pública, jurídicos o institucionales ${ }^{13}$, que en gran medida terminaban por colocar en la palestra pública tópicos tan fundamentales para la formación de la naciente república chilena ${ }^{14}$, como, la codificación del derecho, la administración de justicia, la observancia de la ley, la fundamentación de las sentencias, entre otros ${ }^{15}$.

Siempre ha existido dificultad en precisar fehacientemente cuáles fueron los artículos redactados por Andrés Bello, pues fueron muy variados. Bello publicó en El Araucano tanto trabajos originales como también traducciones y trabajos ajenos $^{16}$. Fue durante esta época (de ardua labor, como muestro más adelante) en que Bello publicó en El Araucano en 1842 la traducción que reedito ahora. $\mathrm{Al}$ menos en este caso podemos dar por seguro no sólo la conexión genética de ese papel de Bello con la traducción de 1842, sino también de su interés como redactor de un medio en el que se trataba de influir a los lectores a través de la publicación de textos relevantes y de un contenido que fuese armónico con la línea editorial de ese medio. Este antecedente es, entonces, relevante para indagar la posible influencia que el contenido de ese texto traducido haya ejercido en Bello, o la que, más ampliamente, haya producido en los lectores de la época.

\section{5. Época del documento y las preocupaciones y encargos de Bello}

Algunos antecedentes de contexto de la época en que fue publicado y de las preocupaciones coetáneas de Bello pueden ser relevantes al respecto.

La publicación en 1842 de este texto relativo al derecho minero francés es relevante para mostrar, una vez más, el interés de Bello en la regulación minera ${ }^{17}$, y fue lo que seguramente le llevó a traducirlo y publicarlo.

En 1842 Bello llevaba doce años en Chile (había llegado en 1829) y ya se encontraba desempeñando una gran variedad de labores en distintos ámbitos de la sociedad, tales como la administración pública, el Senado, la educación, el periodismo, la codificación, entre otros. En efecto, durante esa época, Bello cumplía con un coetáneo encargo ministerial, como oficial mayor del Ministerio de Relaciones Exteriores, Justicia y Culto, puesto desde el cual "se convirtió en el inspirador de la política internacional de Chile y dio forma jurídica a las relaciones del país con otros Estados"18.

Asimismo, durante ese periodo, Bello se desempeñaba como senador de la

${ }^{12}$ Ibíd., p. 28.

${ }^{13}$ Ibíd., p. 23.

${ }^{14}$ GUZMÁN BRITO, Alejandro, cit. (n. 10), p. 40.

${ }^{15}$ Fontaine Aldunate, Arturo, Andrés Bello, formador de opinión pública, en Estudios Públicos, 8 (1982), p. 28, quien destaca el rol de Bello, a través de El Araucano, como formador de opinión pública.

${ }^{16}$ SANTA CRUZ, Eduardo, cit. (n. 11), p. 22.

${ }^{17}$ Algunos antecedentes sobre el interés de Bello en la materia minero ofrezco en VERGARA Blanco, Alejandro, Principios y sistema del derecho minero (Santiago, Editorial Jurídica de Chile, 1992; reimpresión de 2018).

${ }^{18}$ GuZMÁn Brito, Alejandro, cit. (n. 10), pp. 37-38. 
República, puesto que ocupó desde 1837 hasta 1864. Esta función legislativa llevó a Bello a encaminar sus esfuerzos hacia la puesta en práctica de muchas de sus ideas sobre reforma de instituciones públicas y mejora de las funciones sociales, proyectos que terminaron siendo renovadores de la institucionalidad chilena ${ }^{19}$.

Otra preocupación importante para Andrés Bello durante esta época giraba en torno al ámbito educacional en la capital. El cierre del Colegio de Santiago en 1831 marcó el inicio de Bello en la docencia privada, dictando lecciones de derecho natural y de gentes, derecho romano e incluso sobre latín y gramática castellana. Ciertamente, este ejercicio privado de la docencia debió cesar en 1843 con el establecimiento de la Universidad de Chile, institución en la que se desempeñó como rector ${ }^{20}$. Además, cabe destacar que, de las lecciones de derecho romano señaladas, Bello escribió en esa época un libro del ramo que apareció anónimamente en 1843 con el título de Instituciones de derecho romano ${ }^{21}$.

En fin, sin duda el encargo más importante que desempeñó durante esta época fue la tarea de codificar la legislación civil en Chile. Este trabajo comenzó formalmente en 1840, año en el que Andrés Bello presentó al Senado un proyecto de ley dirigido a la creación de una Comisión de Legislación del Congreso Nacional, de la cual pasó a ser miembro, junto a Mariano Egaña. Mientras funcionó esta comisión, de 1840 a 1845, dejó despachado un título preliminar y libros sobre sucesiones, entre otros; los que fueron publicados por partes en El Araucano ${ }^{22}$.

En definitiva, los años cuarenta de su siglo fue una época bastante cargada para Bello, en la cual se podía ver claramente la gran cantidad de intereses y funciones que desempeñó, lo que no haría extraño entonces su interés por la recensión de De Cheppe sobre derecho minero francés, en especial, en razón de su función en la administración pública chilena.

Con dichas anotaciones, por ahora, mostramos la génesis de ambos textos (de la traducción y del papel manuscrito que quedó suelto), su conexión entre sí y el contexto histórico. Queda para otra oportunidad, o para otros autores, a partir de estos antecedentes, la labor de ofrecer la conexión de este texto de 1842 con el interés codificador posterior de Bello, cuyas manifestaciones más próximas en materia minera serán: $1^{\circ}$ ) la propuesta de un Código de Minería (al menos, como programa legislativo), en el art. $4^{\circ}$ del Código Civil de 1857 ; y, $2^{\circ}$ ) la regulación de la naturaleza jurídica de la riqueza mineral en el art. 591 del mismo código. Las amplias disputas que hubo entre los autores de derecho de minería durante el resto del siglo XIX y el XX, en especial respecto del contenido y alcance de este último artículo, seguramente podrán tomar otro tono al reconocer, ahora, en esta traducción de Bello, seguramente algún ánimo suyo de influir con su contenido en esas discusiones, y no meramente llenar páginas del periódico a su cargo.

\footnotetext{
${ }^{19}$ Ibíd., pp. 45-46.

${ }^{20}$ Ibíd., p. 41.

${ }^{21}$ Ibíd.

${ }^{22}$ Ibíd., p. 49.
} 


\section{BibliografíA}

Amunátegui Reyes, Miguel Luis, Nuevos Estudios sobre don Andrés Bello (Santiago, Imprenta, litografía y encuadernación Barcelona, 1902).

Fontaine Aldunate, Arturo, Andrés Bello, formador de opinión pública, en Estudios Públicos, 8 (1982), pp. 23-37.

GUZMÁn BRITO, Alejandro, Andrés Bello codificador: historia de la fijación y codificación del derecho civil en Chile (Santiago, Ediciones de la Universidad de Chile, 1982) II.

GuZmán Brito, Alejandro, Vida y Obra de Andrés Bello (Santiago, Editorial Globo, 2009).

SANTA CruZ, Eduardo, La prensa chilena en el siglo XIX. Patricios, letrados, burgueses y plebeyos (Santiago, Editorial Universitaria, 2010).

Vergara Blanco, Alejandro, Principios y sistema del derecho minero (Santiago, Editorial Jurídica de Chile, 1992; reimpresión de 2018).

\section{ANEXo 1}

TEXTO DE LA TRADUCCIÓN

[con adición de los textos del original no traducidos por Bello]

Reedito, entonces, la traducción realizada por Bello, aparecida en dos partes, con anotación y traducción de los párrafos y notas originales que fueron omitidos por Bello. Anoto, igualmente, al final, la parte en que esta traducción coincide con el papel suelto de Bello que, hasta ahora, se consideraba inédito.

\section{Primera Parte:}

El Araucano $\mathrm{N}^{\circ}$ 612, de 13 de mayo de 1842, p. 1 (columnas 1,2 y 3 ) y p. 2 (col. 1):

Curso de derecho administrativo por M. Cotelle: 3 Tomos $8^{\circ}$, París ${ }^{23} \cdot{ }^{24}$

Se han publicado gran número de obras sobre el derecho administrativo, y sea que abracen la materia en grande, como los sabios tratados de los SS. Cormenin y Macarel, sea que se limiten a una de sus partes, ellas prestan a los interesados y a la administración misma una ayuda de que deben aprovecharse igualmente.

Si la jurisdicción administrativa ha sido por largo tiempo el blanco de mal fundados ataques, dirigidos a su principio y origen, es preciso confesar que eran dignos de una atención seria, cuando se encaminaban a obtener garantías que tenemos ya aseguradas. La publicidad, que parecía temerse para el Consejo de

23 "Este artículo tiene tantas aplicaciones a nuestro régimen administrativo, que nos ha parecido digno de una lectura atenta. Lo hemos traducido del Monitor Universal”. [Nota de Bello].

${ }^{24} \mathrm{El}$ título fue abreviado por Bello. El texto original del título en el Moniteur Universel es el siguiente: "Cours de droit administratif appliqué aux travaux publics, par M. Cotelle, avocat aux conseils du Roi et à la cour de cassation, professeur de droit asministratif á l'école royale des ponts et chaussées. Trois volumes in- $8^{\circ}$, Paris, Carilian-Goury et Dalmont, libraires, quai des Agustins, $n^{\circ} 41$ ". 
Estado, es cabalmente lo que ha dado nueva autoridad a sus decisiones. Sin duda inspiraba confianza por sus luces; pero llamado a ejercer las funciones de juez, era preciso que las partes pudieran hacerse oír ante él. Un debate público y contradictorio presenta a la defensa ventajas preciosas. Los actos de justicia deben ser a toda luz. Esta es una necesidad para las partes, y en cierto modo para el juez mismo.

El Consejo de Estado, tribunal supremo, establece por sus decisiones la unidad, que es una de las condiciones de la justicia. A las tendencias que se extravían, a las variaciones que pueden encontrarse en esas jurisdicciones esparcidas por todo el reino, sustituye una acción fuerte, juiciosa y perseverante. En una palabra, y sean cuales fueren las opiniones acerca de su organización, no podrá menos de reconocer que en sus dictámenes y en sus decretos es un cuerpo independiente y enteramente libre.

La recopilación de estos decretos es un servicio real. Es preciso agradecer a M. Macarel la ilustrada diligencia que ha empleado en una empresa tan útil, continuada en el día por M. Lebon, que ha publicado también los decretos expedidos desde el origen del Consejo hasta la fecha en que principia aquella colección. Pero los abogados del Consejo de Estado no han querido ceñirse a recopilar los actos de la jurisprudencia. Han publicado tratados importantísimos sobre varias partes del derecho administrativo. Y por sus obras, como por sus defensas orales o escritas, se labran sin cesar nuevos títulos a la consideración que tan justamente ha adquirido su orden.

El Curso de derecho administrativo aplicado a los trabajos públicos, publicado recientemente por $\mathrm{M}$. Cotelle, uno de ellos, ocupa un lugar muy distinguido entre los libros de jurisprudencia administrativa. M.Cotelle, fuera de sus extensos conocimientos como jurisconsulto, se ha encontrado en la situación más favorable que era posible para componer esta obra. Encargado hace años de la enseñanza del derecho administrativo en la escuela de puentes y calzadas, ha tenido que dedicarse a un estudio especialísimo sobre los asuntos concernientes a esta materia, y lo ha hecho con fervor y fruto. Brillan en toda su obra una crítica sabia, y una ilustrada apreciación de las especies en que debía fundar sus doctrinas.

Cuando dimos cuenta de la primera edición, indicamos algunos vacíos que se han llenado después. Una tabla analítica que echábamos [ d e ] menos entonces, hace más fácil ahora consultar la obra, y presenta al mismo tiempo una especie de resumen de los principios generales que el autor desenvuelve en ella.

[col. 2] Esta segunda edición contiene además dos tratados nuevos, uno sobre la legislación de las minas y canteras, y el otro sobre los caminos vecinales.

M. Cotelle se remonta sin cesar a la verdadera fuente, es decir, a la discusión de las leyes, para ilustrar los principios de la jurisprudencia. Su obra ofrece desde luego una análisis completa de los debates de estos últimos años en las dos Cámaras, no solo sobre las leyes adoptadas y promulgadas, sino también sobre proposiciones que no llegaron a convertirse en leyes, como las relativas a los aluviones de los ríos, a las aguas termales, etc. ${ }^{25}$. Al tratar de cada materia, enuncia primeramente los hechos históricos y los intereses sociales a que el

${ }^{25}$ Omite aquí Bello algunos detalles menores, de referencia. 
legislador ha puesto la mira; y de estas consideraciones generales desciende a la explicación analítica de la ley y a las controversias que ha hecho nacer.

El capítulo De las minas, que solo constaba de algunas páginas en la primera edición, en la presente ha recibido adiciones e ilustraciones extensas, de manera que ha llegado a ser un verdadero tratado sobre la materia; y como las minas han sido más particularmente el objeto de nuestros estudios, consagraremos una parte de este artículo a ese asunto, cuya importancia ha sido muy bien comprendida y demostrada por el autor.

En efecto, la legislación de las minas, por los intereses numerosos que abraza, no podía menos de fijar su atención. En todos tiempos, los estadistas y los administradores se han manifestado penetrados de la magnitud de esos intereses; y siempre se ha reconocido que la acción y la vigilancia del gobierno eran necesarias para conservar a la sociedad riquezas preciosas, de que un beneficio mal entendido no la dejaría tal vez sacar partido.

¿Pero cuál es el principio en virtud del cual debía ejercerse esa acción y esa vigilancia? ¿Es el Estado el verdadero y único dueño de las riquezas que abriga la tierra en sus entrañas? ¿Este título es el que le faculta para intervenir en la defensa y protección de las minas, como cosa suya? O por el contrario ¿procede esa intervención de aquel otro principio menos absoluto, pero no menos imperioso: que la sociedad no debe hallarse indefensa contra empresas que pueden comprometer sus intereses, y en virtud del cual su gobierno, que es su protector natural y legal, es llamado a velar sobre ellos y a protegerlos? Mucho se ha escrito sobre estas dos hipótesis, que se reducen a decir, por una parte, que las minas son propiedad pública, y por otra, que son propiedad particular, y que en este último sistema la acción gubernativa tiene la mira de impedir que el propietario, sea quien fuere, abuse de lo suyo.

La Asamblea constituyente se ocupó en el examen de estas teorías. En ellas habló Mirabeau por la última vez. El asunto no parece a primera vista que fuese a propósito para inspirar los grandes movimientos tan familiares a aquel ilustre orador. Sin embargo se le vio emplear en él la superioridad de su talento, y se admiran con mucha razón los discursos pronunciados en esta discusión por aquella voz elocuente, ya tan próxima a extinguirse. Él dio a conocer que las minas, por su posición en el seno de la tierra, y por el método que se sigue para beneficiarlas, no podían mirarse como dependencias absolutas de una superficie, que está dividida entre gran número de propietarios. Subiendo al origen de las sociedades, manifestó que la partición de las tierras no había podido abrazar sino la superficie sola, sino los campos destinados al cultivo, en favor de la comunidad reunida para la agresión como para la defensa; y que si esta división era simple y fácil, si se prestaba a todas las modificaciones que pudiesen resultar, ya de los convenios pacíficos, ya de la conquista, no sucedía lo mismo con las minas. No por eso era su ánimo vindicar su dominio para el Estado. Quería solo que fuesen [col. 3] laboreadas y beneficiadas bajo la inspección del gobierno, porque este era el único medio eficaz de conservar en la nación riquezas preciosas, que por su especial naturaleza no podían abandonarse a un régimen de libertad absoluta. El gobierno era el delegado de la nación: velaba en que no se viesen comprometidas 
sus necesidades; y le pertenecía por tanto hacer las concesiones, pero sin desconocer el derecho de preferencia adquirido a los propietarios de la superficie. Tal fue el principio fundamental de la ley de 1791; pero se fue más allá: aquella ley permitió a todos los propietarios laborear, sin concesión alguna, en sus tierras, hasta 100 pies de profundidad. Semejante disposición no podía producir sino la anarquía. Dictada por escrúpulos mal entendidos sobre los derechos del propietario, dio una herida funesta al objeto benéfico que se trataba de obtener. Nos hallábamos en medio de numerosas y acaloradas oposiciones, y se trató de transigir así entre principios contrarios; pero la solución, colocándose bajo el punto de vista del interés general, no fue acertada, como sucede casi siempre que en vez de cortar la dificultad, se crean por una pretendida conciliación disposiciones contradictorias y dificultades nuevas. Es preciso, no obstante, confesar que la cuestión de propiedad era difícil y compleja; pero lo que debía dominar en esta cuestión era la utilidad pública. Una legislación sobre las minas (no podemos inculcarlo demasiado) no debe tener otro móvil ni proponerse otro objeto que la utilidad pública. Ahora bien, ¿no es evidente que un país, como la Francia, donde la propiedad esté dividida al infinito, donde no haya unidad ni concierto, donde todo el mundo pueda ponerse a laborear a su libre albedrío o su capricho, sin regla y sin que nadie vigile sobre las operaciones, se perderían riquezas preciosas para la sociedad, y por una imprevisión fatal se comprometería la suerte y se dilapidaría la herencia de las generaciones futuras?

Más si la ley de 1791 no alcanzó el objeto que se propusieron sus autores, tuvo al menos la ventaja de hacer cesar un orden de cosas que había excitado vivas y legítimas reclamaciones. Bajo el imperio de los abusos del derecho de regalía, derecho cuya naturaleza y origen mismos son materias de controversia, se habían visto conceder mercedes que abrazaban provincias enteras. En vano procuraron algunos de nuestros reyes introducir el buen orden en esta parte de la administración; el favor, los empeños, las importunidades de los cortesanos, arrancaban títulos, que en manos de sus tenedores ocasionaban un agio escandaloso. Entonces, como después, se emitían acciones que la credulidad pública arrebataba, y se hacían caudales con las ruinas de los ilusos. Las especulaciones inmorales que se han producido en estos últimos tiempos son, a este respecto, una triste y vergonzosa repetición de los desórdenes que otras épocas vieron nacer, y que fueron marcadas por ellas, como por la nuestra, con una justa reprobación. Fácil es conocer que en tales circunstancias era imposible que prosperase el laboreo de minas; y así fue en efecto, con algunas raras excepciones. Debía pues pensarse en mejorar la ley. Así, cuando se propuso la cuestión en la Asamblea Constituyente, excitó una atención general. Algunos años antes Turgot había procurado dar alguna luz a la materia; pero por grande que sea la autoridad de este venerado nombre, es preciso decir que Turgot no acertó a dar una buena solución. En su sistema el que tenía derecho a labrar una mina era el primer ocupante. El propietario de la superficie cavaba en su campo, llegaba a una veta o un manto, y por esto sólo era suya la propiedad de la mina. Pero el propietario vecino había tenido igual suerte en sus tierras. Primera causa de disputa. Después continuaba cada cual sus labores, y se encontraba el uno con el otro, a riesgo de derribarlo y destruirlo 
todo. Este derecho del primer ocupante era en [p. 2, col. 1] realidad una cosa inaplicable, imposible. Era organizar la guerra en las extraña de la tierra, como si no nos bastase con las que turban su superficie. Para remediar tantos males, apelaba Turgot a la equidad natural: ¡sueño de un hombre virtuoso! Estas teorías han sido perfectamente apreciadas por M. de Villefosse, en su Riqueza Mineral, obra que vivirá como un monumento de ciencia y legislación, en que el ingeniero ha sabido elevarse a la altura del publicista y del ministro $\left.{ }^{[26}\right]$.

Cuando él escribía, no estaba aún en vigor la nueva legislación sobre minas. La ley promulgada el 21 de abril de 1810 había sido precedida de discusiones que duraron algunos años. El emperador tomó gran parte en ellas; y si en algunos puntos se modificaron sus opiniones en el curso de estos prolongados debates, al menos se puede ver que en esto, como en todo, sabía dominar las más altas cuestiones. Esta le impresionó largo tiempo; y no es extraño que la promoviese en su consejo: entonces el guerrero se transformaba en legislador ${ }^{27}$.

[Pero esta preocupación lo siguió más allá incluso, y podemos juzgar por el intercambio que tuvo, al mes de septiembre de 1806, en Metz, con el prefecto y un joven ingeniero en minas, el señor Beaunier, que daba desde entonces expectativas tan bien realizadas desde entonces, $\mathrm{y}$ cuyo cuerpo que el honró por su mérito y por sus trabajos deplora su perdida prematura] $\left[{ }^{28}\right]$.

\footnotetext{
${ }^{26}[$ [El señor Cotelle no indicó esta remarcable obra entre aquellos que él cita como útiles para consultar sobre la legislación y la jurisprudencia de las minas. Es sin embargo uno de aquellos de los que más podemos aprender al respecto; y el señor Cotelle mismo seguramente hubiera pagado buen precio, no nos lo cuestionamos, para aprovecharse de las lumbreras y de la ciencia de un autor como este, cuya opinión tiene tanta autoridad.] [Traducción de nota omitida por Bello]

${ }^{27} \mathrm{~A}$ la vuelta de sus grandes batallas, descalzadas apenas las espuelas, se dirigía al Consejo de Estado. Oíase ruido de armas a la puerta y tres redobles de cajas, y el ujier gritaba: el emperador, Señores. Napoleón se encaminaba aceleradamente a su silla, saludaba, se sentaba, se cubría, mientras sus oficiales, y a veces algunos príncipes extranjeros se mantenían en silencio a su espalda con la cabeza descubierta.

Si en otras partes no encontraba obstáculos la voluntad de Napoleón; no era lo mismo en su Consejo. Sin embargo del grande influjo que tenía por la autoridad de su voz, hasta el punto de haberse podido decir que era conquistador por la palabra no menos que por las armas, no por eso es menos cierto que todas las opiniones se manifestaban a su presencia con la mayor libertad; el emperador tenía muchas veces que luchar contra ellas. "Algunas veces", dice M. Cormenin, "se las había con M. Treilhard, lógico obstinado, atleta intrépido, que no soltaba fácilmente a su antagonista imperial; y solía decir familiarmente que el ganar una disputa a Treilhard le constaba más trabajo que una batalla". [Nota del Monitor]

${ }^{28}$ [Traducción del párrafo que omite Bello] [La siguiente larga nota, que está en el original francés, no fue traducida por Bello:

"He aquí como el señor Beaunier daba cuenta de esta conferencia, al momento mismo que ella acababa de terminar:

«El emperador. Es una parte interesante aquella de las minas. Es necesario que fijemos más particularmente su legislación. Suspirará después de una reorganización.

«Respuesta. Es cierto que el cuerpo de las minas espera esa gracia de Su Majestad.

«El emperador (hablándole al prefecto). Hemos discutido ya largamente a propósito de aquello, pero sin llegar a acuerdo sobre los medios de conciliar las pretensiones de los mineros
} 
Todo el mundo convenía en que era necesario variar la legislación de 1791, que, procurando reprimir abusos, solo había logrado suscitar nuevos desórdenes. En vano una instrucción ministerial de 1801, había tentado, substituyéndose a la ley, corregir sus imperfecciones. Era indispensable que interviniese el poder legislativo para fijar reglas positivas en una materia de controversia. El Código Civil había proclamado el principio: que la propiedad de la superficie acarreaba la propiedad de lo subterráneo. Es verdad que en él mismo se preveían e indicaban modificaciones, que se renovaban para las ordenanzas especiales de minas. Esto era decir de antemano, que cuando se discutiese la ley sobre minas, se tendría bastante latitud para adoptar el principio que pareciese más en harmonía con el objeto de la legislación. Mas en lugar de hacerlo así, se engolfaron los legisladores en teorías y abstracciones. No se quiso decir a las claras que se quitaba al propietario del suelo el goce de la mina contenida en su fondo, ni se quiso dársela en términos formales, ni atribuirla al Estado. Se tuvo mucho cuidado de no dar a entender que se trataba de un derecho de propiedad pública. Nada de eso. Para hurtar el cuerpo a la dificultad, se imaginó considerar las minas como una especie de bienes no definidos, como propiedad de un género indeterminado que habría de recibir de las mercedes otorgadas por el gobierno el carácter y los efectos de las propiedades ordinarias. Se creía dejar a salvo el principio del Código Civil, porque se creaba a favor del propietario del suelo, si él mismo no obtenía la merced, un reconocimiento de señorío de parte del que la obtuviese en lugar de él. Esta solución parecía ponerlo todo en harmonía, principios, derechos, necesidades, intereses. En medio de todas estas distinciones más o menos sutiles, se consagraba de un modo expresísimo el desposeimiento del propietario del suelo, desposeimiento tal, que no se le dejaba ni aun el derecho de preferencia, como

con el derecho de propiedad. El derecho romano y los principios consagrados por el constituyente son difíciles de ajustar.

«El prefecto. Señor, experimentamos cada día cuan insuficiente es la ley de 1791. Sería tal vez útil, por el bien del asunto, que el gobierno a través de intercambios se volviera propietario del suelo y que lo explotara él mismo.

«El emperador. (Un poco acaloradamente) Nosotros nos abstendremos lo más posible de explotar por nosotros mimos; en Francia el gobierno siempre se encuentra tentado lamentablemente de querer efectuar trabajos del estilo de las minas. No escucharemos estas propuestas: los ingenieros están destinados a vigilar los trabajos... La ley de la constituyente de la cual usted habla no es además tan favorable a los propietarios como pensáis.

"El ingeniero (tomando la palabra, a pesar que él no fue interrogado). Señor, ella es al menos tan vaga y contiene tales contradicciones que termina por obstaculizar a cada paso la marcha de la administración.

"El emperador. El propietario tiene derechos respetables.

"El ingeniero. Parece imposible de confiarle sin peligro la tarea de explotar las minas contenidas en el fondo de sus tierras. La forma de los yacimientos mineros en el seno de la tierra, no tiene, la mayoría de las veces, ninguna especie de relación con la división territorial en la superficie.

«El emperador. Es una materia contenciosa, y sobre la cual volveremos pronto... (Aquí el movimiento de cabeza con el cual S. M. cierra las discusiones hace de despido.) Debimos pues abandonar el lugar al momento cuando comenzaba a calmar mis ánimos, y cuando me preparaba a abordar el fondo de la cuestión”".] 
bajo la ley de 1791 . Se sentía bien que era preciso hacerlo así [ $\left.{ }^{29}\right]$ : se tenía razón para hacerlo $\left[{ }^{30}\right]$, pero se temía decirlo. (Concluirá)

\section{SEgunda PARTE}

El Araucano $\mathrm{N}^{\circ}$ 613, de 20 de mayo de 1842, p. 1 (columnas 1,2 y 3 ):

\section{Curso de derecho administrativo aplicado a las obras públicas: por M. Cotelle. (Conclusión)}

Por lo demás, cualquier sentido que el legislador de 1810 atribuyese a la ley, y de cualquier principio que entendiese derivar la disposición que confiere al gobierno el derecho de hacer mercedes de minas, este derecho está sancionado. La ley, creando una p r o p i e d a d n u e v a, la hizo perpetua e inconmutable, y en la liberalidad de esta creación, dio los mismos caracteres a las mercedes temporales cuyo plazo no estaba cumplido en $1810{ }^{[31}$. Las discusiones que han ocurrido en las dos cámaras durante las últimas sesiones, han parado en demostrar nuevamente que las reglas establecidas por la ley de 1810 son las que mejor cuadran con el interés general. El gobierno, colocándose esta vez fuera de las abstracciones, arrostró sin vacilar las cuestiones más fundamentales de la materia, que fueron resueltas según se proponía, después de largos y brillantes debates, sostenidos por una y otra parte con una grande energía de talento. La más grave de estas cuestiones era sin duda la del retracto de las mercedes, y triunfó como las otras, porque subsistió evidente que una propiedad instituida en el interés general debe desde luego, y siempre, beneficiarse según ese interés, y que el mercedario que no cumple con los cargos que le impone su título mismo abdica las ventajas que ese título le había conferido.

Colocando en una especie de inviolabilidad al que no hacía caso de sus obligaciones, se le favorecía con privilegio monstruoso, y se le consagraba un derecho de uso y de abuso que no podía pertenecerle, estando sometido a una

\footnotetext{
${ }^{29}$ [... No obstante que la propiedad del suelo conlleva la propiedad de la parte superior y de la parte inferior (art 552 del Código Civil), sin embargo de ello, es un principio importante en nuestro derecho público y consagrado por nuestras leyes que, debido a altas consideraciones de interés general, las $\mathrm{m}$ i n a $s$ ya sean metálicas, ya sean de carbón, que se encuentren en las heredades particulares, están sin embargo a la disposición del gobierno, en el sentido que estas no pueden ser explotadas, incluso por los propietarios de la superficie, que no sea en virtud de una concesión deliberada en consejo de Estado, bajo la vigilancia de ingenieros, etc. (Proudhon, du Dom. Publ. [Del Dominio Público], t. I Ir, p. 95).] [Traducción de nota omitida por Bello.]

${ }^{30}$ Véase sobre este asunto el tratado De la legislación de las minas y canteras en Francia y la Bélgica, por M. Delebecque, abogado general de la Corte de Bruselas. [Bello omite, al final, la siguiente frase: "La opinión que nosotros señalamos aquí está de acuerdo con la de este sabio magistrado".]

31 [ M. d'Argeson proponía todo lo contrario en 1832. Propuso nada menos que la revisión de todas las concesiones ya instituidas. El Sr. Odilon Barrot ha señalado muy bien que "esta revisión solo podría llevarse a cabo mediante una retroactividad que hiere todos los principios y que viola los derechos adquiridos sobre la base de las leyes vigentes". En 1816, M. Dugas de Varennes también atacó, pero sin éxito, la ley de 1810. Siempre fue el interés particular el que se sustituía al interés general] [Traducción de nota omitida por Bello].
} 
legislación especial, que concediéndole el uso, proscribía formalmente el abuso, y hallándose además ligado por aquella cláusula general que permite resolver el contrato cuando una de las partes no cumple con las obligaciones que se ha impuesto. Solo entre todos los propietarios, el que lo era por una dádiva de la ley, ¡había de sobreponerse a todas las reglas y de infringirlas impunemente! Tales consecuencias eran inadmisibles; y la legislación, decidiendo que una concesión de mina puede revocarse en ciertos casos, ha mantenido un principio que debía ser aquí tan inflexible como en las demás cosas, cuando el concesionario se expone voluntariamente a que se le aplique.

Tal es la doctrina que profesa con nosotros M. Cotelle, oponiéndose a la de M. Delebecque, con quien sentimos no estar de acuerdo.

Si es verdad que la mina está sujeta a las cargas determinadas por el acto de concesión, ¿extenderemos esta regla hasta imponer al concesionario la obligación de ceder su propiedad sin indemnización, si alguna empresa de utilidad pública exige este sacrificio? M. Cotelle se pronunciaba por la afirmativa. Nosotros hemos emitido en otra parte la opinión contraria $\left.{ }^{[2}\right]$. Nos ha parecido que el interés público podía bien exigir precauciones de seguridad, pero que sería confundir dos cosas muy diversas sacrificar la propiedad a semejantes exigencias. La de las minas es tan sagrada como otra cualquiera: cuando el propietario llena sus obligaciones, debe gozar, como los demás, de lo suyo, y tiene derecho a igual protección.

La Corte de Casación, llamada a fallar sobre una cuestión de esta especie, la ha resuelto recientemente en el mismo sentido que nosotros.

[Si bien la opinión del señor procurador general no haya prevalecido en esta circunstancia, su discurso no se ve reducido en su calidad de monumento precioso sobre un sujeto donde él mostró, como siempre, conocimientos profundos y un admirable talento.] [ ${ }^{33}$ ]

Cuando se ha concedido por el gobierno el permiso de catear una mina en virtud del artículo 10 de la ley de 21 de abril de 1810, no obstante la oposición del propietario del suelo, ¿podrá éste frustrar el permiso declarando que va él mismo a catear?

[col.2] M. Cotelle responde afirmativamente, y tampoco podemos adoptar en esta parte su opinión. La autorización concedida debe hacerse efectiva por el tiempo designado en ella. No debe ser más permitido al propietario de la superficie impedir este efecto, que al propietario de un mineral de hierro de aluvión anular el permiso concedido a un maestro de fragua para beneficiarlo por sí, cuando el propietario no a ha querido emprender el beneficio.

Se creyó largo tiempo que una simple decisión ministerial bastaba para autorizar los cateos contra la voluntad del propietario; pero después se ha reconocido que bajo la palabra g o b i e r n o la ley quería decir, no el ministro, sino el soberano que determina a virtud del informe del ministro. Y en efecto, ¿qué menos puede hacerse, cuando se trata de ocupar los terrenos de un tercero a pesar suyo, que impetrar una orden real?...

${ }^{32}$ [Annales des mines, $3^{\mathrm{e}}$ série, tome XV.] [Nota omitida por Bello].

${ }^{33}$ [Traducción de párrafo omitido por Bello]. 
[Pero no es necesario, como el señor Cotelle intenta establecer, que esta ordenanza sea deliberada en consejo de Estado. Los artículos 16 y 73 de la ley de 1810, que él invoca en relación a este tema, pueden ser citados para probar precisamente lo contrario. Estos exigen explícitamente que las ordenanzas relativas a las concesiones de minas y a los permisos de fábrica sean rendidos de esta forma. El art. 11 no dice nada semejante. Sin embargo, no se discute que no se debe hacer intervenir los reglamentos de la administración pública que en los casos donde esto resulte de una disposición formal de la ley.

Del resto, no basta, como lo indica el señor Cotelle, que los proyectos de las ordenanzas de los cuales se hace mención en los artículos 16 y 73 sean deliberados por el comité de obras públicas, de la agricultura y del comercio, del consejo de Estado; estos deben ser también, y lo son en efecto, examinados en asamblea general del consejo.] [34]

M. Cotelle ha emitido una especie de acusación contra los prefectos, reprochándoles que oponen la fuerza de inercia a ciertas peticiones, que, a derecho $\mathrm{u}$ a tuerto, no les parecen admisibles. El mismo M. Cotelle reconoce que hay demandas absurdas, y aun puede decirse que su ocurrencia es frecuente. ¿No sería pues un nuevo absurdo darles curso? Hartas extravagancias, por no llamarlas de otro modo, han pasado por las cabezas de ciertos explotadores de minas ${ }^{35}$. La administración que substanciase pedimentos inconsiderados o ridículos se haría cómplice de los abusos que está encargada de reprimir; y lejos de censurar su inercia, deberíamos agradecérsela. En cuanto a aquellos que han de venir acompañados de informaciones, si alguna vez se retardan, no es por culpa de los prefectos solos. Todos tienen su parte en ello, y no poca los mismos que los hacen, que, no obstante repetidos avisos, se descuidan en presentar los documentos indispensables. Es preciso ser justo con todos, hasta con los prefectos.

M. Cotelle y M. Delebecque no están de acuerdo en cuanto a la indemnización que ordinariamente se concede a los dueños de la superficie. Las opiniones de M. Delebecque convienen más con las nuestras, sin que por eso queramos generalizar su aplicación. Creemos que esas indemnizaciones no dan siempre a los propietarios una ganancia cualquiera, como dice M. Cotelle; que por el contrario

\footnotetext{
${ }^{34}$ [Traducción de dos párrafos omitidos por Bello].

${ }^{35}$ Robertson en su Historia de América habla de artificios de cierta clase de hombres conocidos en el Perú con el título de cateadores. "Son comúnmente hombres arruinados, que a merced de algunas nociones mineralógicas, ayudados de modales insinuantes, y de aquellas alegres esperanzas que son propias de los proyectistas, se dirigen a las personas opulentas y crédulas, describen con verosimilitud y plausibilidad las señales de riquezas que les ha presentado una veta nueva: producen, si es necesario, muestras del mineral que contiene; $y$ sostienen con una seguridad imponente que la ganancia es infalible y los costos una bagatela: rara vez dejan de persuadir. Se forma una sociedad: cada interesado contribuye una pequeña cuota; se abre la mina; el cateador dirige las operaciones; se encuentran dificultades imprevistas; se pide más dinero", etc. No es el Perú el único país en que se han visto de esos cateadores de minas. [Bello omite, al final, la siguiente referencia: "Histoire de l'Amérique, to. III, pag. 161 et suiv."]
} 
rara vez valen algo; y que la nueva ley dictada en la Bélgica el 2 de mayo de 1837 es mucho más conforme a los intereses y derechos de la propiedad superficial...

[En un inicio, las regalías reservadas al Estado se encontraban consagradas a los gastos de la administración de minas, que tenía así pues un interés personal en la cuestión. De todas las especialidades que fueron suprimidas en 1814 se determinó, como las demás, su retorno al tesoro público. Entonces, esta administración ya no se beneficiará más directamente, como parece creerlo el señor Cotelle. Su intervención, en vez de tener un carácter puramente fiscal que se unía a un impuesto percibido para su propia cuenta, se ejerce hoy en día en el interés de la propiedad de las minas no menos que en el interés del tesoro.

¿La regalía fija atribuida al Estado debe contarse como la tarifa proporcional del censo electoral? El señor Cotelle no cita en este aspecto más que una sentencia de la corte de casación, del 14 de junio 1830, que resuelve la cuestión negativamente. Añadiremos que la ley de 1831 dio una solución contraria y más conforme, según nosotros, a la naturaleza de las cosas.] [ ${ }^{36}$ ]

Si las minas se conceden por miras de utilidad pública, no por eso debe ${ }^{37}$ // ${ }^{38}$ olvidarse en ellas el interés de los propietarios de la superficie. La ley de 1810 ha provisto completamente a ello....

[La ley de 1810 precavió completamente al prescribir las medidas necesarias para que la seguridad pública no fuera comprometida. El artículo 8 de la ley del 27 de abril de 1838, que el señor Cotelle supone fue creado justamente con esa intención, se aplica particularmente a los trabajos i l í c i t o s, emprendidos ya sea por concesionarios, sea por terceros que no tienen concesión: este autoriza a la administración para prohibir estos trabajos inmediatamente, sin perjuicio de las penas a pronunciar por los tribunales por el hecho mismo de la contravención. Un concesionario podría perfectamente ser obligado a cesar los trabajos cuya naturaleza aparente comprometer la seguridad; esta obligación es inherente a la naturaleza misma de la propiedad. Ella no se relaciona en lo absoluto necesariamente a la existencia de una contravención, que es ciertamente el caso al cual hace alusión el artículo 8 de la nueva ley. Si bien este articulo da a la administración la fuerza y la autoridad que le faltaba, y viene así en ayuda de la ley de 1810, hay que reconocer sin embargo que este fue propuesto y adoptado en un orden de ideas que no es exclusivamente el que el señor Cotelle pensó que era necesario conectar] [ ${ }^{39}$ ]

${ }^{36}$ [traducción dos párrafos omitidos por Bello]

${ }^{37}$ Todo el texto que sigue, y hasta el final (salvo los párrafos que agrego ahora, que fueron omitidos por Bello) se corresponde con el papel manuscrito de Bello, que se creía i n é d i t o , al que nos referimos antes. Lo trascribo, a partir de aquí, con sangría especial e indico, al inicio de cada párrafo, los signos: //.

${ }^{38}$ Aquí comienza el manuscrito de Bello, el que es exactamente coincidente con el texto publicado (salvo los párrafos marcados, que fueron omitidos del original).

${ }^{39}$ Bello omitió este párrafo. 
// En la pág. 218 del tomo $2^{\circ}$ de la obra de M. Cotelle encontramos esta proposición: "Mientras no existe concesión ni permiso para el laborío de las substancias minerales y fósiles que contiene un predio, se reputan c a $\mathrm{n}$ e $\mathrm{r}$ a s, y pueden trabajarse como tales, en libre ejercicio del derecho de propiedad". El autor supone que la administración tolera el beneficio de la mina cuya merced no ha otorgado a nadie. Pero de cualquier modo que se mire esa tolerancia, no comprendemos que pueda sacarse de ella la con [col. 3] secuencia a que llega el autor, y que expuesta en los términos que acaban de leerse, no solo se opone a todas las reglas de la materia, sino que está en contradicción con lo que él mismo dice sin cesar y con tanta razón sobre las ordenanzas de minas y sobre el espíritu que las ha dictado. Tomada en su precisión y generalidad, la proposición que emite produciría resultados, que él ciertamente no aprueba. ¿Puede concebirse mayor confusión que la que resultaría de esa libertad de laboríos antes de concederse las minas? Ese régimen aniquilaría nuestras riquezas minerales, y haría ilusorias y sin objeto las cuerdas previsiones de la ley...

[Que el señor Cotelle nos perdone estas reflexiones. Si, en lo referente a las preguntas que venimos de indicar y de algunas otras para las cuales el espacio nos falta, no compartimos todas sus opiniones, estas disidencias parciales no nos podrían impedir de rendir completa justicia al espíritu general de su libro y a la manera en que él resolvió una tarea laboriosa y difícil. Nuestra critica es una prueba de la sinceridad de nuestros elogios. [ $\left.{ }^{40}\right]$

// Hallase la misma erudición en todas las partes de esta grande obra. El tratado de los caminos vecinales, no se distingue menos que el de las minas por las consideraciones que en él se desarrollan, y el gran número de cuestiones nuevas que se resuelven...

[Así la repartición de poderes entre el consejo general y el prefecto, en lo que concierne al voto y a la dirección de caminos de gran comunicación, ofrece una discusión de las más graves en cuanto a sus atribuciones respectivas.] [ $\left.{ }^{41}\right]$

// No es menos interesante la discusión sobre la prescripción de los caminos públicos que no están clasificados como vecinales, y sobre las formas de que se vale el gobierno para poner la industria en movimiento, ya por medio de las adjudicaciones públicas, ya mediante peajes concedidos por tiempo limitado o perpetuamente en los canales, puentes y caminos de hierro, de que resultan multitud de contratos administrativos y de combinaciones fiscales.

[La materias que M. Cotelle había tratado en la primera edición, como ya hemos dicho, reciben en esta grandes novedades; es el caso, ante todo de la organización de puentes y carreteras con todas las aplicaciones de este servicio, tales como la expropiación por razones de utilidad pública, el agotamiento de las marismas, los daños a la propiedad causados por la ejecución de obras públicas, las ganancias de capital que a menudo resultan de su

\footnotetext{
${ }^{40}$ Bello omitió este párrafo.

${ }^{41}$ Bello omitió este párrafo.
} 
proximidad a las propiedades vecinas. Todas estas materias se desarrollan de acuerdo con el último estado de la jurisprudencia, ya sea del Tribunal de Casación o del Consejo de Estado.

[Después de explicar las modificaciones que la propiedad sufre por el efecto de la creación de obras y emprendimientos de esta naturaleza, $\mathrm{M}$. Colette muestra en qué formas el gobierno está poniendo a la industria a trabajar, instándole a invertir su capital en empresas, ya sea a través de licitaciones públicas, o por medio de peajes por tiempo limitado o perpetuos en canales, puentes y ferrocarriles, lo que resulta en una multitud de contratos administrativos y de combinaciones financieras, tales como préstamos, donaciones, garantías de intereses, etc."] [ $\left.{ }^{42}\right]$.

// Sentimos no poder seguir al autor por todas las partes de su obra. Creemos empero, que se deben recomendar particularmente al lector los capítulos consagrados a los caminos reales, a la navegación fluvial, a los canales de navegación, riego o desecación, a los trapiches y molinos de agua, a los establecimientos metalúrgicos, a los talleres que se tienen por peligrosos, insalubres o incómodos, a los conflictos de atribuciones.

// Cuando se considerala multiplicidad de negocios en que los ingenierosson llamados a ocuparse, se puede apreciar la utilidad del curso derecho administrativo aplicado a las obras públicas. M. Bérard introdujo esta enseñanza en la escuela de puentes y calzadas, cuando era director de puentes y calzadas y de minería; y en ello prestó un señalado servicio, no solo a los jóvenes ingenieros, sino a cuantos tengan intereses que ventilar con la administración $\left[{ }^{43}\right]$. M. Cotelle, a quien se encomendó desde entonces esta cátedra, ha hecho ver que comprendía perfectamente su misión; y añadiremos que el modo con que la ha desempeñado le confiere un título honroso, sobre tantos otros que le daban derecho a la estimación pública. // (De Cheppe) $\left.{ }^{[44}\right]$.

${ }^{42}$ Bello omite estos dos párrafos (los que en parte resume).

${ }^{43} \mathrm{La}$ administración que sucedió al señor Bérard, al dar una sanción definitiva a una medida que la experiencia ya había mostrado su ventaja, la completó muy útilmente. Ella encargó al profesor de derecho administrativo de la escuela de puentes y caminos de impartir igualmente las clases para los alumnos de la escuela de minas, y de esta manera respondió a una necesidad reconocida desde hace tiempo. [Nota omitida por Bello]

${ }^{44}$ [Bello omite los cargos del autor] [En el original: DE CHEPPE, maitre des requêtes, chef de la division des mines au ministère des travaux publics.] [Trad.: DE CHEPPE, Director de solicitudes, jefe de la división de minas en el ministerio de obras públicas.] 


\section{ANEXo 2}

IMAGeN DEL MANusCRITO DE Bello

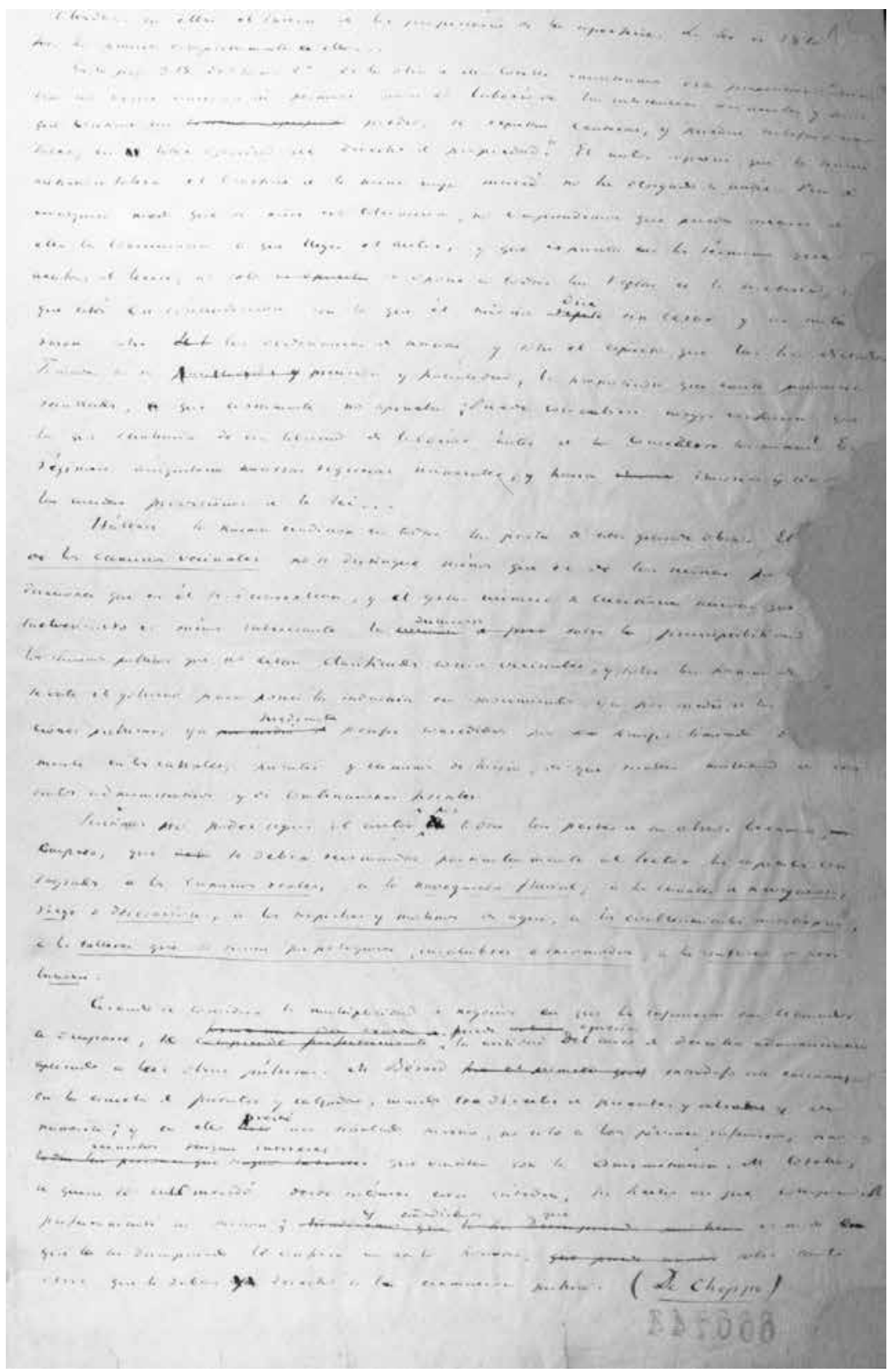

